\title{
DIREITO À VIDA E O DEBATE SOBRE A CRIMINALIZAÇÃO DO ABORTO ${ }^{1}$
}

RIGHT TO LIFE AND THE DEBATE ON THE CRIMINALIZATION OF ABORTION

João Pedro Zorzi OCTAVIANO²

ISSUE DOI: $10.21207 / 2675-0104.2018 .806$

\begin{abstract}
RESUMO
Um dos maiores debates do século XXI é o direito à vida. Atualmente procuramos diversos meios para identificar onde começa a vida, mas nem sempre isso é moralmente aceito na sociedade. Para garantir que os direitos e garantias fundamentais estabelecidos na Constituição Federal de 88 e os tratados internacionais ratificados pelo Brasil sejam respeitados, o projeto faz um panorama jurídico, científico e filosófico sobre o tema. Além disso, debatemos também sobre o aborto e como essa prática pode influenciar negativamente a vida das mulheres. Partindo desses preceitos, demos luz a um projeto rico em análises científicas e debates sociais.
\end{abstract}

Palavras-chave: Direito à vida; Aborto; Direitos e garantias fundamentais.

\section{ABSTRACT}

One of the greatest debates of the 21st century is the right to life. We are currently looking for a variety of ways to identify where life begins, but this is not always morally accepted in society. To ensure that the fundamental rights and guarantees established in the Federal Constitution of 88 and the international treaties ratified by Brazil are respected, the project provides a legal, scientific and philosophical overview on the subject. In addition, we also discuss abortion and how abortion can negatively influence women's lives. Starting from these precepts, we gave light to a project rich in scientific analysis and social debates.

Keywords: Right to life; Abortion; Fundamental rights and guarantees.

\footnotetext{
${ }^{1} \mathrm{O}$ presente artigo sintetiza a monografia de conclusão da pesquisa, realizada para o Programa Interno de Bolsas de Iniciação Científica (PIBIC 2017-2018) da Faculdade de Direito de Franca (FDF), Franca/SP.

${ }^{2}$ Discente da Faculdade de Direito de Franca (FDF), Franca/SP. Bolsista do Programa Interno de Bolsas de Iniciação Cientítica (PIBIC 2017-2018).
} 


\section{INTRODUÇÃO}

O direito à vida é não somente uma cláusula pétrea como também o mais fundamental de todos os direitos, pois garante e preserve que todos os demais sejam estabelecidos. Essa premissa, muito defendida por constitucionalistas do Brasil, é provavelmente uma síntese de todas as pesquisas realizadas nesse projeto. O legislador estabeleceu o direito à vida como fundamental por entender que sua ausência prejudica os demais direitos. Nesse projeto, procuramos entender o que a ciência classifica como vida e os preceitos e fundamentos constitucionais que orientam o tema.

O entendimento do ordenamento jurídico brasileiro de que os direitos fundamentais do nascituro já são consagrados desde o momento da concepção garante que o direito à vida é fonte primária. Na doutrina, é praticamente consenso de que a dignidade da pessoa humana é ofendida sempre que o ser humano for rebaixado a objeto e tratado como coisa.

O Código Civil Brasileiro garante no art. $2^{\circ}$ que a personalidade civil da pessoa começa do nascimento com vida; mas a lei põe a salvo, desde a concepção, os direitos do nascituro.

Alexandre de Moraes observa a importância desse dispositivo infraconstitucional como direito fundamental, vejamos:

O direito à vida é o mais fundamental de todos os direitos, já que se constitui em pré-requisito à existência e exercício dos demais direitos $^{3}$

Com base nesse preceito, compreendemos que a natureza jurídica de todos os direitos depende justamente da vida, motivo pelo qual foi impetrado não somente no Código Civil, mas também na Constituição Federal de 88 como direito fundamental.

Nessa perspectiva, completa Mário Luiz Delgado:

O nascituro não é uma simples massa orgânica, uma parte do organismo da mãe, ou, na clássica expressão latina, uma portio viscerum matris, mas um ser humano, com dignidade de pessoa humana, independentemente de as ordens jurídicas de cada Estado lhe reconhecerem ou não personificação jurídica. ${ }^{4}$

\footnotetext{
${ }^{3}$ MORAES, Alexandre de. Direito Constitucional. 17.ed. São Paulo: Atlas, 2005. p.26.

${ }^{4}$ Acórdão do Supremo Tribunal de Justiça de Portugal - Processo: 436/07.6TBVRL. P1. S1.
} 
$\mathrm{O}$ entendimento do ordenamento jurídico brasileiro de que os direitos fundamentais do nascituro já são consagrados desde o momento da concepção garante que o direito à vida é fonte primária. Na doutrina, é praticamente consenso de que a dignidade da pessoa humana é ofendida sempre que o ser humano for rebaixado a objeto e tratado como coisa.

$\mathrm{O}$ Brasil ratificou acordos internacionais para tutelar o direito à vida, expressos no art. $6^{\circ}$ do Pacto Internacional de Direitos Civis e Políticos e no art. $4^{\circ}$, inciso I da Convenção Americana de Direitos Humanos - Pacto de São José da Costa Rica, consolidando o respeito e a integridade física do nascituro:

Art. $6^{\circ}$ do Pacto Internacional de Direitos Civis e Políticos, 1966 : "O direito à vida é inerente ao ser humano. Este direito deverá ser protegido pela lei. Ninguém poderá ser arbitrariamente privado da vida."

Artigo $4^{\circ}$, inciso I da Convenção Americana de Direitos Humanos - Pacto de São José da Costa Rica: "Toda pessoa tem o direito de que se respeite sua vida. Esse direito deve ser protegido pela lei e, em geral, desde o momento da concepção. Ninguém pode ser privado da vida arbitrariamente."

A Constituição Federal prevê e assegura no Art. 5ª a inviolabilidade do direito à vida, o considerando um direito fundamental, tendo em vista que sem a vida é impossível desfrutar de qualquer outro direito, tendo-o como o direito que é fonte para todos os outros direitos.

Todavia, no mesmo Art. $5^{\circ}$ da constituição federal, inciso VI, decorre que é inviolável a liberdade de consciência e de crença sendo assegurado o livre exercício, o considerando como um direito fundamental.

\footnotetext{
Art. $5^{\circ}$ Todos são iguais perante a lei, sem distinção de qualquer natureza, garantindo-se aos brasileiros e aos estrangeiros residentes no País a inviolabilidade do direito à vida, à liberdade, à igualdade, à segurança e à propriedade, nos termos seguintes: [...] VI - é inviolável a liberdade de consciência e de crença, sendo assegurado o livre exercício dos cultos religiosos e garantida, na forma da lei, a proteção aos locais de culto e a suas liturgias; $\left(\mathrm{CF}\right.$, art. $\left.5^{\circ}, \mathrm{IV}\right)$
}

\section{O LUGAR DOS DISCURSOS RELIGIOSOS NO BRASIL}

O constituinte de 1988 inseriu o direito à vida, no art. $5^{\circ}$ caput da Constituição Federal, como cláusula pétrea. 
“Todos são iguais perante a lei, sem distinção de qualquer natureza,
garantindo-se aos brasileiros e aos estrangeiros residentes no País
a inviolabilidade do direito à vida, à liberdade, à igualdade, à
segurança, e à propriedade.”

O Brasil é um estado laico, ainda que a maioria da população seja cristã. Foi o que a CF 88 estabeleceu no art. $5^{\circ}$ VI. A religião tem um papel essencial na vida do ser humano para orientá-lo civil e espiritualmente, o que leva as pessoas seguir os bons costumes e preservar a boa-fé. Contudo, numa democracia, todos os temas podem ser discutidos, inclusive aqueles que possam ferir os preceitos de uma religião. Para sanar esta dúvida em relação ao Brasil, na última pesquisa realizada pelo Ibope, foi constatado que $80 \%$ da população brasileira é contrária ao aborto. Esse índice subiu em 2\% desde 2010. Com essa porcentagem, é notório que a sociedade brasileira é contrária a prática de aborto.

\section{O PROBLEMA DO ABORTO NO DIREITO PENAL}

\subsection{ARGUMENTOS FAVORÁVEIS À CRIMINALIZAÇÃO}

Já foram citados diversos argumentos jurídicos em relação à criminalização do aborto, mas de forma mais específica, analisaremos os argumentos favoráveis à criminalização não somente sob a esfera penal, mas também através do prisma da saúde física e mental da gestante, um crivo ético da sociedade, os direitos do nascituro e o respeito à dignidade $\mathrm{e}$ à vida humana.

$\mathrm{O}$ argumento jurídico defendido no artigo $5^{\circ}$ da Constituição estabelece que a inviolabilidade do direito à vida é cláusula pétrea e o seu parágrafo segundo estabelece que os direitos e garantias expressos na Constituição não excluem outros decorrentes do regime e princípios por ela adotados, proibindo qualquer interpretação restritiva dos direitos consignados neste artigo.

$\mathrm{O}$ argumento de que em algumas semanas depois da fecundação o feto é apenas um amontoado de células. Se isso fosse verdade, estaríamos delimitando o início da vida de forma artificial somente para nutrir interesses alheios. Como sabemos, a teoria adotada pelo Brasil é a concepcionista, em que a vida se inicia no momento da concepção. Não há 
como traçar um limite sobre onde começa a vida de acordo com esse pensamento, se assim fosse, a vida se iniciaria com a batida do coração? Pois há pessoas adultas que só vivem em virtude de um marca-passo e precisam dessa ajuda externa para gerar as batidas de seus corações. No caso da atividade cerebral, o que aconteceria com as pessoas que estão em coma? Poderíamos simplesmente matá-las? O problema é que quando você estabelece um falso critério sobre onde começa a vida de uma criança, você também estabelece esse critério que pode ser usado na vida de adultos.

$\mathrm{O}$ argumento da retroatividade diz respeito sobre a moralidade do aborto e suas contradições. Se os pais podem escolher ou não abortar o próprio bebê no ventre da mãe, por que não poderiam fazer isso fora do ventre?

O argumento de que os métodos contraceptivos são extremamente seguros. É quase que matematicamente impossível engravidar com o uso de dois métodos contraceptivos combinados e usados corretamente. $\mathrm{O}$ preservativo masculino usado corretamente previne em aproximadamente $98 \%$ as chances de uma gravidez indesejada, sem falar na prevenção de doenças sexualmente transmissíveis. A pílula anticoncepcional previne em 99,9\% uma gravidez indesejada. Combinados esses dois métodos, uma gravidez é impossível. O que falta é consciência no ato sexual e o uso correto e combinado dos diversos métodos contraceptivos que existem no mercado.

O argumento de que a mãe possui controle sobre seu corpo é contraditório, pois a mãe tem controle sobre seu pŕoprio corpo, mas não corpo de seu filho (a). Nessa linha de pensamento, a historiadora Ana Caroline Campagnolo traça uma crítica extremamente importante acerca do tema:

É verdade que as mulheres têm direitos, inclusive direito à busca pela felicidade. Mas também é verdade que uma bebê feminino tem o direito à vida, o direito de nascer. Por que o direito ao conforto da mulher adulta deve ser mais valorizado que o direito de viver (e mesmo sofrer) de uma mulher que está ainda na barriga da mãe? O direito das mulheres é proporcional ao seu tempo de vida? Mulheres de 30 anos, $160 \mathrm{~cm}, 60 \mathrm{~kg}$, grávidas e infelizes, têm mais direitos que mulheres com 12 semanas, $8 \mathrm{~cm}$ e 28 gramas?

O argumento de que a família não possui condições financeiras é absolutamente inaceitável uma vez que existem diversos programas sociais e políticas públicas preventivas como a distribuição gratuita de preservativos e pílulas anticoncepcionais. Além disso, o governo brasileiro 
possui programas sociais voltados para famílias carentes, sendo injustificável fazer qualquer ligação sobre o assunto.

$\mathrm{O}$ argumento da criminalização procura explicar que as mulheres continuarão a fazer aborto, só que ilegalmente. Se partirmos desse princípio, deveríamos revogar praticamente todo o Código Penal. A conduta continuará sendo repulsiva e o crime o mesmo, portanto as pessoas apenas irão praticá-lo sem o poder punitivo do Estado. O Código Penal serve justamente para afastar essas condutas repugnantes da sociedade.

$\mathrm{O}$ argumento da saúde pública deveria ser tratado também sob a ótica do quão mal faz às mulheres que praticam o aborto. Não apenas fisicamente, mas psicologicamente. Há diversos casos em que as mulheres se arrependem de ter praticado o aborto e enfrentam profundas crises de depressão e problemas relacionados. Sem falar nos riscos do próprio aborto para a vida da mulher.

$\mathrm{O}$ argumento de que os pais abandonam as mães ao descobrirem a gravidez. Se pensarmos dessa maneira, seria permitido uma mãe matar seu próprio filho se fosse abandonada pelo seu parceiro depois da sua gestação? O argumento não é completamente insustentável e mostra como é cruel a atitude das pessoas que pensam dessa maneira. No Brasil já existem leis que obrigam os pais a pagarem pensões para os filhos e que se descumpridos os pagamentos serão condenados e direcionados para a penitenciária separados dos presos comuns. Não podemos partir da premissa que todos os homens são ruins e abandonam suas esposas e filhos, porque isso não é verdade. Mas precisamos sustentar a ideia de que existe sim um poder estatal que está sempre vigilante e exerce imposição nos pais que não cumprem os deveres relativos aos seus filhos.

$\mathrm{O}$ argumento do estupro é o mais polêmico e é nele que se concentra todas as forças progressistas para permitir que o aborto seja irrestrito para todos os casos. No caso do aborto, a legislação penal já permite que a mãe possa optar por escolher ou não continuar com a gestação. Mas o que realmente falta é uma legislação penal mais rígida para os crimes contra a dignidade sexual. Infelizmente vemos casos de estupradores que ficam pouco tempo atrás das grades e voltam a cometer as mesmas atrocidades. Mas isso é um caso de segurança pública e reeducação carcerária. 
Nesse tópico faremos uma análise dos argumentos contrários à criminalização do aborto.

$\mathrm{O}$ argumento de que o aborto é uma questão de saúde pública, pois independente da lei proibir a conduta, o aborto continuará existindo e sendo praticado, no entanto, as mais ricas costumam ter um aborto bemsucedido por fazerem em clínicas clandestinas, enquanto as mais pobres procuram meios alternativos e ainda mais perigosos para realizar o aborto.

$\mathrm{O}$ argumento de que razões religiosas não podem influenciar a escolha da mãe, pois independente da conduta não ser aceita por grande parte da sociedade, religiosa e até mesmo não-religiosa, é uma escolha intrínseca da mãe optar por realizar ou não o procedimento de aborto.

$\mathrm{O}$ argumento de que os pais abandonam os seus filhos e por esse motivo as mães são obrigadas a cuidar sem auxílio ou com auxílio mínimo. $\mathrm{O}$ que provoca uma série de problemas psicológicos para a mãe e para o próprio filho, já que na ausência de um pai, terá que ser criado exclusivamente pela mãe.

$\mathrm{O}$ argumento de que o feto não sente dor até a décima segunda semana de gestação, porque suas terminações nervosas são formadas apenas depois. Há estudos que mostram que as terminações nervosas podem ser formadas antes ou depois e isso é um tema extremamente controverso na medicina.

O argumento de que os métodos contraceptivos falham, pois não há nenhum método contraceptivo 100\% seguro. Além disso, as políticas públicas falham na distribuição de métodos preventivos nas comunidades carentes.

O argumento da rejeição do filho advindo de uma gravidez indesejada que poderá ser maltratado ou abandonado, sujeitando-se a traumas psíquicos.

O argumento da preservação da saúde mental materna, visto que uma gravidez indesejada pode comprometer psicologicamente a mãe.

$\mathrm{O}$ argumento de que as mulheres devem ter o livre arbítrio para realizar o procedimento de aborto nos casos de estupro, pois os traumas psicológicos podem se tornar piores no futuro.

\section{$4 \quad$ A VIDA COMO BEM JURÍDICO-PENAL}

O aborto jamais poderá ser considerado como problema de saúde pública, pois saúde é o estado de equilíbrio biopsicossocial e espiritual. 
Uma prática que implica matar o filho no ventre de sua genetriz não pode ser considerado saúde, mas homicídio. Hipócrates, um médico grego, já havia proposto esse julgamento. Cerca de quinhentos anos antes de Cristo, os gregos já sabiam que aborto era homicídio e juraram jamais utilizar seu saber para realizar esse assassinato.

No Brasil, a proteção do embrião se inicia desde a concepção, assim descreve o artigo $2^{\circ}$ do Código Civil. Já o Código Penal criminaliza o aborto porque se atenta contra o bem personalíssimo da vida do óvulo fecundado. Contudo, como já citado anteriormente, não é punível o aborto se a gravidez provém de estupro, quando há risco de morte da mãe ou no caso de anencefalia fetal, conforme precedente julgado pelo Supremo Tribunal Federal na ADPF 54. Neste último caso, existe um confronto entre juristas que defendem o atual posicionamento, de que a vida humana nos casos de anencefalia absolutamente inviável e gera uma profunda dor para os pais e aos próprios filhos, pelo fato de que diante de tal anomalia, é certa uma morte extremamente prematura da criança. Os juristas dessa corrente de pensamento garantem que essa situação não pode ser confundida com o aborto eugênico, que atende interesses particulares e egoísticos da gestante e que não pode ser tolerado em hipótese alguma, por infringir, não somente o direito à vida do concepto, mas também o próprio princípio da dignidade do ser humano. Por outro lado, juristas à favor da vida descrevem que esse aborto é encoberto com um falso manto de moralidade, já que se utilizam desta anomalia como tentativa de ampliar o aborto para outras situações. A premissa de que o feto com anencefalia pode viver durante um curto espaço de tempo é extremamente falha, pois não existe nenhum diagnóstico que possa prever o futuro, tampouco as condições de vida do feto podem ser usadas como argumento para se permitir o aborto. Milhares de crianças nascem diariamente com algum distúrbio ou problema de saúde e vivem dias, meses ou até dezenas de anos. Se ponderarmos, uma criança que nasce com problemas cardiovasculares, não poderia morrer até mais rápido que uma criança com anencefalia? Nem por isso, permitimos o aborto de milhares de inocentes com deficiências cardiovasculares. Mais uma vez na balança da ponderação, quantas crianças não morrem já nas primeiras semanas vítimas de doenças ou até mesmo no próprio parto em virtude de complicações? É absolutamente impossível prever essas atrocidades e é justamente por isso que esta corrente se posiciona contrária à ADPF 54. 


\section{5}

\section{O DEBATE NO SUPREMO TRIBUNAL FEDERAL}

Nos últimos anos o Supremo Tribunal Federal propôs debater temas que são de competência exclusiva do legislativo, o que ficou conhecido como ativismo judicial.

A primeira turma do Supremo Tribunal Federal decidiu no dia 29 de novembro de 2016 que o aborto deveria ser descriminalizado até o terceiro mês de gestação, contudo, a decisão tinha efeito somente num caso concreto. Desde então diversos juristas começaram a questionar a legitimidade do poder judiciário interferir nessas matérias, sob o argumento de que ultrapassa os limites estabelecidos pela Constituição Federal de 88. Se o Supremo Tribunal Federal pudesse exercer poderes legislativos, os partidos com menor força no Congresso Nacional poderiam recorrer seus interesses privados no poder judiciário, aumentando significativamente suas chances de aprovação, pois enquanto um projeto de lei depende normalmente de uma maioria simples dos 513 deputados federais e 81 senadores, no Supremo Tribunal Federal bastaria que 6 ministros se posicionassem a favor.

\section{CONCLUSÃO}

O estudo sobre o direito à vida e o debate sobre a criminalização do aborto analisou conceitos jurídicos, éticos, morais e científicos. O trabalho teve como objetivo responder questionamentos acerca do aborto no âmbito de incidência da Constituição da República Federativa do Brasil, Código Penal e Código Civil. Além disso, o trabalho também apresenta alternativas pragmáticas no tange aos problemas de segurança pública que se relacionam ao tema.

O direito das mulheres foi preservado em todos os momentos, garantindo o direito à vida de acordo com a legislação vigente e propondo punir rigorosamente os crimes contra a dignidade sexual. Juristas renomados serviram de base para construir um projeto rigidamente estruturado e preocupado com diversos temas correlacionados.

O projeto também inclui variadas leis e tratados internacionais, literatura estrangeira, pesquisas oficiais, reflexões sobre discursos religiosos e profunda argumentação jurídica.

Não obstante, foram objetos de debate a ADPF 54 e a ADPF 442, esta última ainda em análise pelo Supremo Tribunal Federal. 
Podemos entender como a sociedade brasileira pensa a respeito da prática de aborto analisando todos os conceitos envolvidos na elaboração desse estudo. Compreendemos que a religião influencia os costumes e os conceitos morais, mas que nem sempre consegue repelir a prática de aborto, como no caso da Irlanda. Contudo, a sociedade brasileira ainda se mostra de modo geral contrária a legalização do aborto.

\section{REFERÊNCIAS BIBLIOGRÁFICAS}

MORAES, Alexandre de. Direito Constitucional. 17.ed. São Paulo: Atlas, 2005.

DINIZ, Maria Helena. Curso de Direito Civil. 12. ed. São Paulo: Saraiva, 1996.7 v. v. 1: Teoria Geral do Direito Civil.

BRANCO, Paulo Gustavo Gonet. Curso de Direito Constitucional. $5^{\text {a }}$ Ed. São Paulo: Editora Saraiva, 2010.

BRANCO, Paulo Gustavo Gonet. Direitos Fundamentais em espécie. Direito à vida. In MENDES, Gilmar Ferreira; COELHO, Inocêncio Mártires; BRANCO, Paulo Gustavo Gonet. Curso de direito constitucional. 4.ed. rev. atual. São Paulo: Saraiva, 2009.

TAYLOR, Charles. Sources of the Self: the making of the modern identity. Cambridge: Harvard University Press, 1989.

Código penal interpretado, Julio Fabbrini Mirabete, Renato N. Fabbrini. - $7^{\text {a }}$ ed. - São Paulo: Atlas, 2011 